Check for updates

Cite this: RSC Adv., 2018, 8, 18589

\title{
Formation of different shell structures in lithium- rich layered oxides and their influence on electrochemical properties $\uparrow$
}

\author{
Kai Cao, ${ }^{\text {ab }}$ Kangping Wang, ${ }^{\text {ab }}$ Taotao Shen, ${ }^{\text {b }}$ Wenlou Wang (D) *abcd \\ and Dongming Chen ${ }^{a}$
}

A lithium-rich layered oxide with different shell structures was synthesized by a simple wet-chemical surface deposition method. X-ray diffraction (XRD), scanning electron microscopy (SEM), transmission electron microscopy (TEM), X-ray photoelectron spectroscopy (XPS), and other techniques were applied to characterize the crystal structure, morphology, and micro-structure of the samples. The surface of the lithium-rich layered oxide can successively produce island-like spinel, ultra-thin spinel, and thick two-phase (spinel and amorphous manganese oxides) separation shell layers with an increase in the coating amount. The formation process of the different shell structures and the effect of the shell structure on the lattice parameters were discussed. The different shell structures play an important role in the electrochemical performance of the lithium-rich oxide. In particular, when the coating amount is 1 wt\%, the lithium-rich material with a uniform $\mathrm{Li}_{4} \mathrm{Mn}_{5} \mathrm{O}_{12}$ spinel shell layer exhibits superior electrochemical performance, and can maintain a discharge capacity of $209.9 \mathrm{~mA} \mathrm{~h} \mathrm{~g}^{-1}$ and $166.8 \mathrm{~mA} \mathrm{~h} \mathrm{~g}^{-1}$ at rates of $2 \mathrm{C}$ and $5 \mathrm{C}$.

Received 9th April 2018

DOI: $10.1039 / c 8 r a 03038 c$

rsc.li/rsc-advances

stability and dreadful rate performance. ${ }^{7-9}$ Therefore, it is urgent to solve these shortcomings in order to obtain lithiumrich layered oxides with excellent electrochemical performance.

Many efforts have been employed to remedy these drawbacks. For instance, surface coating, ${ }^{10-13}$ heterogeneous element doping, ${ }^{14,15}$ construction of nano-size particles, ${ }^{16,17}$ acid treatment, ${ }^{18}$ and blending with lithium intercalation compounds ${ }^{19}$ have been discussed. Among them, surface coating has been proven to be an effective method to improve the cycle stability and high rate performance of lithium-rich layered materials. Various materials, including various oxides, fluorides, phosphates, and carbon materials, have been used to form coating layers. ${ }^{20-22}$ On the other hand, these coated materials have either low ionic conductivity or poor electronic conductivity or are even electrochemically inactive, which may hamper the further improvement of the electrochemical properties of lithium-rich cathode materials. Currently, the superior electrochemical performance of spinel materials has attracted much attention as a result of their excellent ionic and electronic conductivity. ${ }^{23,24}$ Spinel materials have been widely used as coating materials for lithium-rich cathode oxides. Su's group reported that, by using the spinels $\operatorname{LiNi}_{0.5} \mathrm{Mn}_{1.5} \mathrm{O}_{4}$ and $\mathrm{LiMn}_{2} \mathrm{O}_{4}$ as a protective shell layer, the electrochemical performance of lithium-rich cathode materials is greatly improved. ${ }^{25,26}$ The spinel $\mathrm{LiNi}_{0.5} \mathrm{Mn}_{4.5} \mathrm{O}_{12}$ was also used by Xie et al. ${ }^{27}$ as a coating, and the lithium-rich oxide equally showed good electrochemical properties. Although some reports have been focused on lithium ion cathode materials with layered spinel core-shell 
structures, there is little investigation of $\mathrm{Li}_{4} \mathrm{Mn}_{5} \mathrm{O}_{12}$ as a shell material in lithium-rich layered oxides.

In this work, we reported a lithium-rich layered oxide encapsulated by the ultra-thin spinel $\mathrm{Li}_{4} \mathrm{Mn}_{5} \mathrm{O}_{12}$ through a simple surface deposition method. The $\mathrm{Li}_{4} \mathrm{Mn}_{5} \mathrm{O}_{12}$ spinel shell material is generated by the solid-state reaction of manganese oxide with lithium. This lithium comes from the in situ diffusion of the lithium-rich cathode material during heat treatment. In order to form the $\mathrm{Li}_{4} \mathrm{Mn}_{5} \mathrm{O}_{12}$ shell layer, the heat treatment temperature is chosen to be $400{ }^{\circ} \mathrm{C}$. The basis for choosing this temperature is that $\mathrm{Li}_{4} \mathrm{Mn}_{5} \mathrm{O}_{12}$ is decomposed into $\mathrm{Li}_{2} \mathrm{MnO}_{3}$ and $\mathrm{LiMn}_{2} \mathrm{O}_{4}$ when the temperature is higher than $500{ }^{\circ} \mathrm{C} .{ }^{28}$ Hence, $400{ }^{\circ} \mathrm{C}$ is the relative optimum temperature for the formation of $\mathrm{Li}_{4} \mathrm{Mn}_{5} \mathrm{O}_{12}$. In principle, the diffusion amount of the lithium in the lithium-rich layered oxide to the interface is finite under certain conditions (heat treatment temperature and time). This will lead to the formation of different shell structures with changes in the coating amount. Therefore, the formation of different shell structures is discussed in this paper. We also considered the influence of the shell structure on the lattice parameters of the core particle and the electrochemical properties.

\section{Experimental and computational methods}

\section{Synthesis of the lithium-rich layered oxide}

Layered $\mathrm{Li}_{1.24} \mathrm{Ni}_{0.12} \mathrm{Co}_{0.13} \mathrm{Mn}_{0.51} \mathrm{O}_{2}$ was synthesized by a conventional co-precipitation method followed by the conduction of a solid-state reaction at high temperature in air. Analytical grade chemicals $\mathrm{NiSO}_{4} \cdot 6 \mathrm{H}_{2} \mathrm{O}, \mathrm{CoSO}_{4} \cdot 7 \mathrm{H}_{2} \mathrm{O}$, and $\mathrm{MnSO}_{4} \cdot \mathrm{H}_{2} \mathrm{O}$ in stoichiometric amounts were dissolved in $75 \mathrm{ml}$ distilled water, while excess $2 \mathrm{~mol} \% \mathrm{Na}_{2} \mathrm{CO}_{3}$ (ensuring the precipitation of all the transition metals) was dissolved in the same volume of distilled water. The molar concentration of the two solutions was $2 \mathrm{M}$. Afterwards, the two solutions were simultaneously dropped into the reactor at a constant feed rate $\left(0.58 \mathrm{ml} \mathrm{min}^{-1}\right)$ through two peristaltic pumps. The solidliquid mixture was continuously stirred (rotating speed: 400 $\mathrm{rpm} \mathrm{min}^{-1}$ ) for $13 \mathrm{~h}$ under a nitrogen atmosphere and the aging temperature was maintained at $55^{\circ} \mathrm{C}$. After aging, the obtained carbonate precursor was carefully filtered, washed, and dried in a vacuum at $100{ }^{\circ} \mathrm{C}$ for $6 \mathrm{~h}$. Then, the carbonate precursor underwent pre-calcination at $500{ }^{\circ} \mathrm{C}$ for $5 \mathrm{~h}$ in air and was thoroughly mixed with the required amount of LiOH. Afterwards, the mixture was calcined at $900{ }^{\circ} \mathrm{C}$ for $12 \mathrm{~h}$ in a muffle furnace and then cooled to room temperature to obtain the target sample (pristine sample).

\section{Synthesis of samples with different shell structures}

Firstly, solids $\mathrm{MnSO}_{4}$ and $\mathrm{Na}_{2} \mathrm{CO}_{3}$ were dissolved in $20 \mathrm{ml}$ and $10 \mathrm{ml}$ distilled water, respectively. Then, the prepared lithiumrich oxide powder was dispersed in the $\mathrm{MnSO}_{4}$ aqueous solution, and the $\mathrm{Na}_{2} \mathrm{CO}_{3}$ solution was added dropwise to the suspension solution. After all of this, the turbid solution continued to be mechanically stirred for $1 \mathrm{~h}$, and was then filtered, washed, and dried in a vacuum oven at $100{ }^{\circ} \mathrm{C}$ for $2 \mathrm{~h}$. Finally, these carbonate coated lithium-rich materials were heat treated at $400{ }^{\circ} \mathrm{C}$ for $3 \mathrm{~h}$ in air. According to their different mass ratios (lithium-rich oxide/carbonate), they were designated as samples of $0.5 \mathrm{wt} \%, 1 \mathrm{wt} \%$ and $3 \mathrm{wt} \%$, respectively.

\section{Structure characterization}

The crystal structures of the samples were identified by powder X-ray diffraction performed using a Philips X'pert pro X-ray diffractometer $(\mathrm{Cu}-\mathrm{K} \alpha$ radiation, $\lambda=1.5418 \AA)$ in the $2 \theta$ range from $10^{\circ}$ to $70^{\circ}$. The morphologies of the different samples were observed with a scanning electron microscope (SEM, JEOL JSM6700F) and a transmission electron microscope (TEM, JEOL2010). The chemical element composition was examined quantitatively by an inductive coupled plasma atomic emission spectrometer (ICP-AES) with an emission spectrometer (Optima 2010 DV, Perkin-Elmer). The specific surface area of the pristine sample was measured by the adsorption-desorption of $\mathrm{N}_{2}$ using an ASAP 2020 instrument. X-ray photoelectron spectroscopy (XPS) was carried out using a Perkin-Elmer RBD upgraded PHI5000C ESCA system. Curve fitting of the XPS spectra was performed using a CasaXPS program and the binding scale was calibrated from the hydrocarbon contamination using the $\mathrm{C} 1 \mathrm{~s}$ peak at $284.8 \mathrm{eV}$. Differential Scanning Calorimetry (DSC) analysis of the different samples in the delithiated state was carried out on an SDT Q600 from ambient temperature to $400{ }^{\circ} \mathrm{C}$ at a rate of $10{ }^{\circ} \mathrm{C} \mathrm{min}^{-1}$ under air flow.

\section{Electrochemical measurements}

The electrode material was prepared with a weight ratio of $80 \%$ active material, $10 \%$ acetylene black, and $10 \%$ binder (polyvinylidene fluoride, PVDF, dissolved in $N$-methyl-2-pyrrolidone, NMP, in a certain volume). Then, the mixture was stirred for $6 \mathrm{~h}$ in a closed environment, and afterwards covered in aluminium foil and dried in a vacuum oven at $120^{\circ} \mathrm{C}$ overnight. The 2032 type coin cells were assembled in an argon-filled glove box $\left(\mathrm{H}_{2} \mathrm{O}\right.$ $\left.<0.1 \mathrm{ppm}, \mathrm{O}_{2}<0.1 \mathrm{ppm}\right)$. Metal lithium foil was used as the counter electrode and reference electrode, and a porous Celgard 2325 membrane was used as the separator. The electrolyte consisted of $1 \mathrm{M} \mathrm{LiPF}_{6}$ dissolved in ethylene carbonate (EC), dimethyl carbonate (DMC), and fluoroethylene carbonate (FEC) at a weight ratio of $3: 5: 2$ (Beijing Institute of Chemical Reagents, P. R. China). The constant current charge and discharge mode was achieved with a multichannel battery tester (Shenzhen Neware, BTS, P. R. China) in the voltage range of 2.0$4.6 \mathrm{~V}$. Cyclic voltammetry (CV) was operated between 2.0 and $4.8 \mathrm{~V}$ at a $0.1 \mathrm{mV} \mathrm{s}^{-1}$ scanning rate. All electrochemical operations were performed at room temperature.

\section{Density functional theory (DFT) calculations}

Periodic DFT calculations were carried out based on a normconserving pseudo-potential and the Perdew-Wang (PW91) functional in Cambridge Sequential Total Energy Package of Materials Studio (version 8.1). The K-S valence states of $\mathrm{Mn}$ (4s3d), O (2s2p), and Li (2s) were expanded in a plane wave basis up to a kinetic energy of $830 \mathrm{eV}$, while the separation of the $k$ - 
points is $0.05 \AA^{-1}$. The results show that the free energy has converged at this precision. As a transition metal, the intensively localized $3 \mathrm{~d}$ electrons of manganese will produce a selfinteraction error within the DFT calculation, which must be corrected. Therefore, a Hubbard $U_{\text {eff }}$ value must be used to describe the interaction of manganese with $3 \mathrm{~d}$ electrons. ${ }^{29}$ The empirical value of $U_{\text {eff }}$ was measured by comparing the calculated and experimental $\mathrm{LiMO}_{2}$ crystal structures in this work. When the $U_{\text {eff }}$ value is $0.5 \mathrm{eV}$, the lattice parameters $a(2.8686 \AA)$ and $c(14.2745 \AA)$ of $\mathrm{LiMO}_{2}$ after optimization are very close to the experimental values ( $a$ : $2.8531 \AA$, $c: 14.2643 \AA$ ).

Currently, it is still a controversial issue whether lithium-rich layered oxide exists as a solid solution or a composite phase structure. In this calculation, we only intend to study the structural changes of the samples after the diffusion of lithium in the synthesis process, so we consider the structure of $\mathrm{LiMO}_{2}$ ( $\left.\mathrm{M}=\mathrm{Li}_{0.24} \mathrm{Ni}_{0.12} \mathrm{Co}_{0.13} \mathrm{Mn}_{0.51}\right)$ to be a solid solution. In order to cope with the hexagonal structure of lithium-rich oxides, we also assume that $\mathrm{LiMnO}_{2}$ is in the $R \overline{3} m$ structure. ${ }^{30,31}$ Since there are only a small proportion of the lithium ions diffusing from the lithium-rich oxide by heating, the effect on the whole symmetry of the hexagonal structure can be ignored. Therefore, the atomic fractional coordinates were fixed in the optimization.

\section{Results and discussion}

As shown in Fig. S1a, $\dagger$ the lithium-rich layered oxide with micron-sized spherical secondary particles is assembled by primary sub-micron (100-300 $\mathrm{nm}$ ) particles. The morphology of the samples before and after coating shows almost no change (Fig. S1b-d $\dagger$ ). In order to investigate the influence of the coating amount on the surface morphology and structure, the samples were characterized by TEM and HRTEM. The smooth surface of the sub-micron primary particles is observed in the uncoated sample (Fig. 1a). The (003) plane of the lithium-rich oxide with $0.47 \mathrm{~nm}$ lattice fringe spacing is clearly shown in Fig. 1b. When $0.5 \mathrm{wt} \%$ manganese carbonate is coated, the TEM image shows a negligible morphology change (Fig. 1c). Interestingly, some island-like well-crystalized substances are formed on the particle surface (Fig. 1d), as indicated by the black arrows. The interplanar spacings of the island-like substances are calibrated to be 0.247 and $0.472 \mathrm{~nm}$ (see the inset in Fig. 1d), which are consistent with the (311) and (111) planes of cubic spinel. With the coating amount increased to $1 \mathrm{wt} \%$, the HRTEM image indicates that a uniform coating layer is formed on the primary particle surface of the lithium-rich layered oxide (Fig. 1f). The coating layer of about $2 \mathrm{~nm}$ thickness clearly presents fine lattice fringes. The interplanar distance is about $0.471 \mathrm{~nm}$, which is well indexed to the (111) plane of cubic spinel. When the coating amount further increases to $3 \mathrm{wt} \%$, some small particles (marked by the white arrows in Fig. 1g) adhere to the surface of the primary particle. It should be pointed out that the coating layer consists of crystal particles and amorphous materials (Fig. 1h). The former is ascribed to the spinel material according to the information provided by the lattice fringes; the latter may be amorphous manganese oxides. Hence, the surface

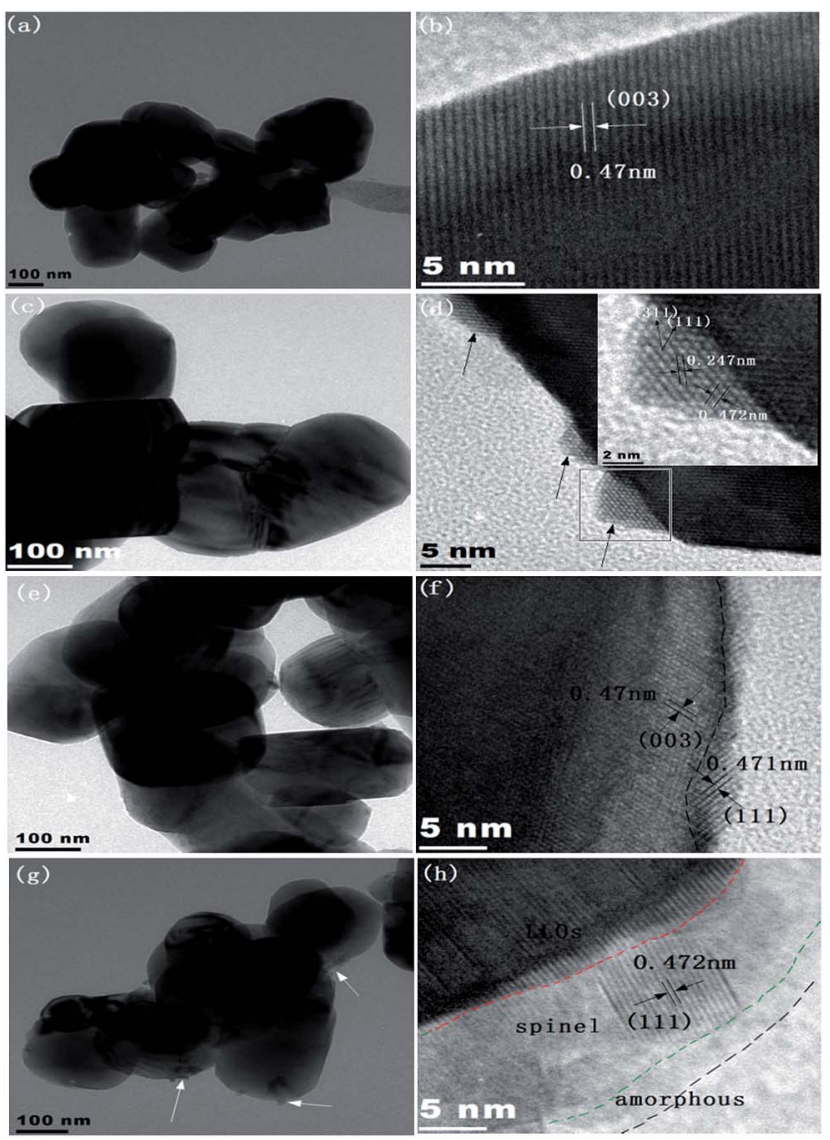

Fig. 1 TEM images and HRTEM images of different samples: $(a, b)$ pristine sample, (c, d) $0.5 \mathrm{wt} \%$ sample, (e, f) $1 \mathrm{wt} \%$ sample, and (g, h) 3 wt\% sample; the inset in the top right corner of (d) is an enlarged image of the gray square.

of the $3 \mathrm{wt} \%$ sample consists of three components, namely, lithium rich layered oxides (LLOs) as the inner core, spinel material as the intermediate layer, and amorphous manganese oxide as the outer layer.

The results shown in Fig. 1 illustrate that different coating amounts result in different shell structures under the present experimental conditions. It is worth briefly discussing the formation of the different shell structures. Firstly, the precursor amount of the coating layer plays an important role. Initially, the surface of a particle is partially covered by the precursor while its concentration is very dilute. By increasing the precursor concentration gradually, the surface is wholly covered, and the thick two-phase separation layer can be formed. Secondly, the reaction temperature and time are crucial. The $\mathrm{Li}_{4} \mathrm{Mn}_{5} \mathrm{O}_{12}$ spinel layer should result from lithium ions diffusing from the lithium-rich material to the manganese oxides (the intermediate products of the spinel layer). The identification of the $\mathrm{Li}_{4} \mathrm{Mn}_{5} \mathrm{O}_{12}$ spinel will be highlighted in the following section. Since the experimental temperature is lower, the distance for the lithium ion diffusion is short, so the coating layer formed on the particles is very thin. This may be the reason why amorphous material exists in the coating layer in the $3 \mathrm{wt} \%$ sample. Amorphous material may originate from the decomposition of the precursor $\left(\mathrm{MnCO}_{3}\right)$ at $400{ }^{\circ} \mathrm{C}$. 
On the basis of the above discussion, another question is raised now. The departure of partial lithium ions from the lithium-rich oxide should have an influence on the lattice parameters of the lithium-rich oxide. The experimental results demonstrate this point. The XRD patterns, including the Rietveld refinement of the different samples, are shown in Fig. 2a. All peaks can be indexed as the $\alpha-\mathrm{NaFeO}_{2}$ structure with the space group $R \overline{3} \mathrm{~m}$, and the superlattice peak between $20^{\circ}$ and $23^{\circ}$ is a characteristic of the $\mathrm{Li}_{2} \mathrm{MnO}_{3}$-type integrated phase. ${ }^{32-34}$ To investigate the crystal structure changes of the different samples, Rietveld refinement was carried out using JADE software. Fig. $2 \mathrm{~b}$ shows the changes in the cell volume $V$ and lattice parameter $c$ values with coating amount. The shrinking variation of the $V$ and $c$ values is roughly linear while the coating amount is up to $1 \mathrm{wt} \%$. After that, the lattice parameters are basically unchanged. This result is in agreement with the observations from the HRTEM (Fig. 1f and h). Thus, the reachable conclusion is that the concentration of lithium ions in the lithium-rich oxide has an influence on its lattice parameters.

In order to further understand the origin of the change in the lattice parameters after coating, theoretical calculations were conducted based on DFT. The required lithium ions in the spinel layer $\left(\mathrm{Li}_{4} \mathrm{Mn}_{5} \mathrm{O}_{12}\right)$ must be derived from the lithium-rich material by diffusion. Hence, the inner core lithium-rich oxide will certainly suffer from a loss of lithium after the coating treatment. In view of this change in the lithium amount, two models of a $2 \times 2 \times 1$ supercell were constructed (Fig. 3 ). Since $\mathrm{Mn}$ is the main element of the transition metal layer, $\mathrm{Mn}$ is used instead of the other metal elements for the simplified calculation. The bulk $\mathrm{LiMnO}_{2}$, which has a normal stoichiometry without a lithium deficiency, is displayed in Fig. 3a. The lithium deficiency model, in which a single lithium atom (red arrow) is removed, is shown in Fig. 3b. DFT optimization gave rise to lattice parameter $c$ values of $14.2745 \AA$ for the normal structure and 14.2037 $\AA$ for the lithium deficient structure. This reflects the fact that the decrease in the lithium concentration in the (a)

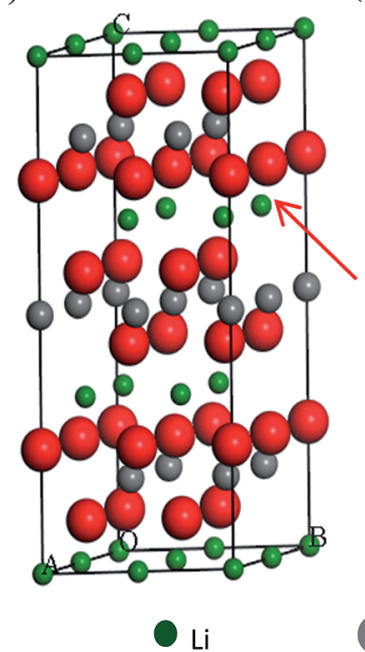

(b)

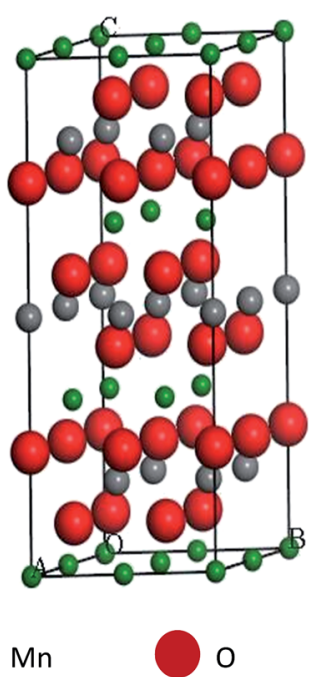

Fig. 3 The optimized structure model of a $\mathrm{LiMnO}_{2} 2 \times 2 \times 1$ supercell, (a) a primitive cell; (b) a lithium atom removed cell.

primitive cell tends to reduce the $c$ value of the lattice, which is consistent with the XRD experiment.

Based on the analysis of XRD and DFT, it can be concluded that the lattice shrinkage of the coated samples is due to the departure of the lithium atom from the lithium-rich material. Simultaneously, the lithium ion diffusion amount is sensitive to the heating-treatment environment, which results in little change in the lattice parameters between the $3 \mathrm{wt} \%$ sample and the $1 \mathrm{wt} \%$ sample. Therefore, $1 \mathrm{wt} \%$ may be the best coating amount for the formation of a uniform spinel material layer. According to the above assumption, it is necessary to calculate the thickness of the $\mathrm{Li}_{4} \mathrm{Mn}_{5} \mathrm{O}_{12}$ spinel coated layer in the $1 \mathrm{wt} \%$ sample. The thickness of the spinel layer $\left(\mathrm{Li}_{4} \mathrm{Mn}_{5} \mathrm{O}_{12}\right)$ can be calculated as well using the following equation:

$$
l=\frac{V}{S}=\frac{m / \rho}{S}
$$
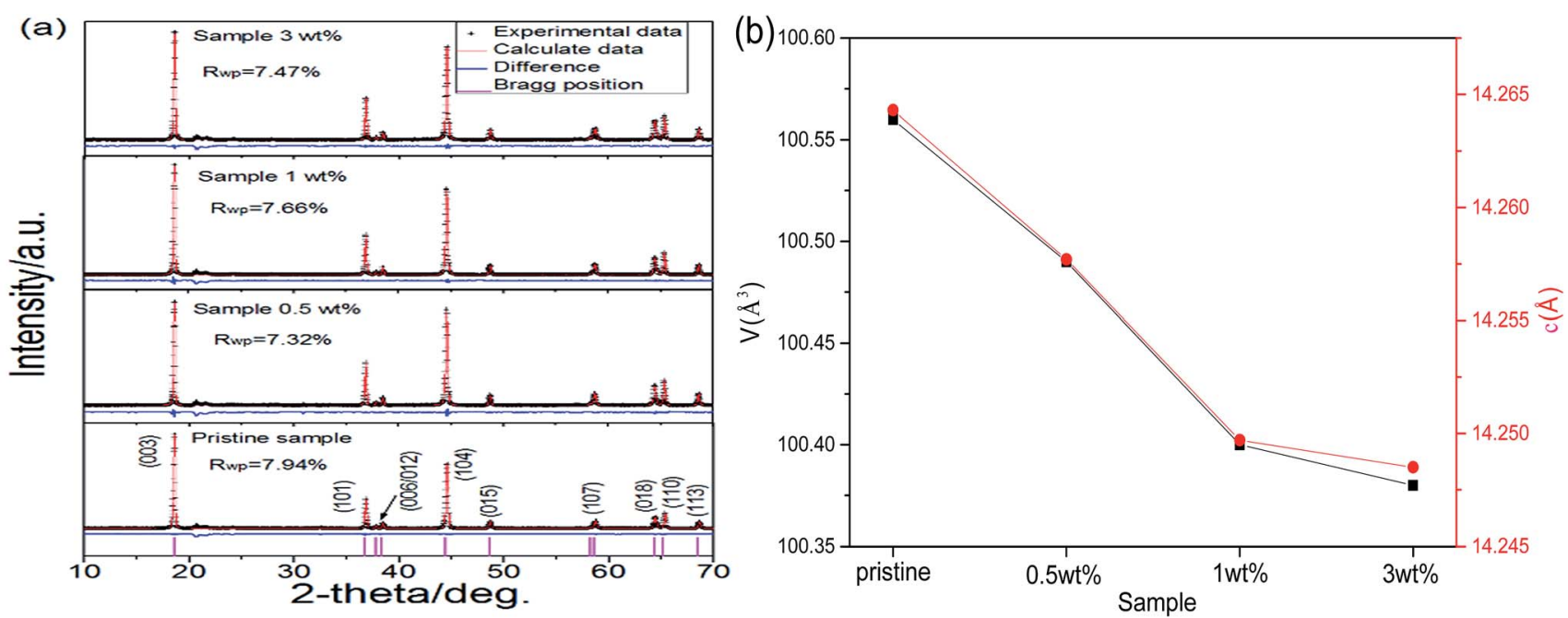

Fig. 2 (a) XRD patterns including the Rietveld refinement of different samples. (b) The variations in the volume and $c$ axis. 
where $l, S$, and $V$ are the thickness, area, and volume of the coating layer. The area can be obtained from the specific surface area of the lithium-rich oxide by BET $\left(1.3963 \mathrm{~m}^{2} \mathrm{~g}^{-1}\right), \rho$ is the true density of the spinel $\mathrm{Li}_{4} \mathrm{Mn}_{5} \mathrm{O}_{12}\left(4.03 \mathrm{~g} \mathrm{~cm}^{-3}\right)$, and $m$ is the mass of $\mathrm{Li}_{4} \mathrm{Mn}_{5} \mathrm{O}_{12}$. It is assumed that the spinel $\mathrm{Li}_{4} \mathrm{Mn}_{5} \mathrm{O}_{12}$ is evenly spread on the surface of the lithium-rich layered oxide. Meanwhile, $1 \mathrm{wt} \%$ of manganese carbonate is decomposed into manganese oxides, and the manganese oxides, after completely embedding in the lithium, can also form a spinel material of about $1 \mathrm{wt} \%$ relative to the tremendous weight of the lithiumrich layered oxide. Hence, the lithium-rich material ( $1 \mathrm{~g}$ ) is coated with $1 \mathrm{wt} \% \mathrm{Li}_{4} \mathrm{Mn}_{5} \mathrm{O}_{12}$ spinel, and the mass of the spinel material is $0.0101 \mathrm{~g}$. According to the equation, the corresponding thickness is $1.8 \mathrm{~nm}$, which is almost identical to the result from the HRTEM image (Fig. 1f). Therefore, this indicates that a coating amount of $1 \mathrm{wt} \%$ is the best proportion for forming a homogeneous $\mathrm{Li}_{4} \mathrm{Mn}_{5} \mathrm{O}_{12}$ spinel coating layer.

In this section, surface techniques and electrochemical methods were used to study the spinel material. Fig. 4a shows the X-ray photoelectron spectra of the $1 \mathrm{wt} \%$ sample and pristine sample in the $\mathrm{Mn} 2 \mathrm{p}$ region, from which it can be found that both spectra are almost identical to each other. This result indicates that the manganese valence in both samples is the same. The Mn $2 \mathrm{p}_{3 / 2}$ binding energy is $642.4 \mathrm{eV}$, which matches well with that of $\mathrm{Mn}^{4+}$, reported in the literature. ${ }^{35}$ In the $\mathrm{O} 1 \mathrm{~s}$ spectra, two peaks are observed in the pristine sample, but only

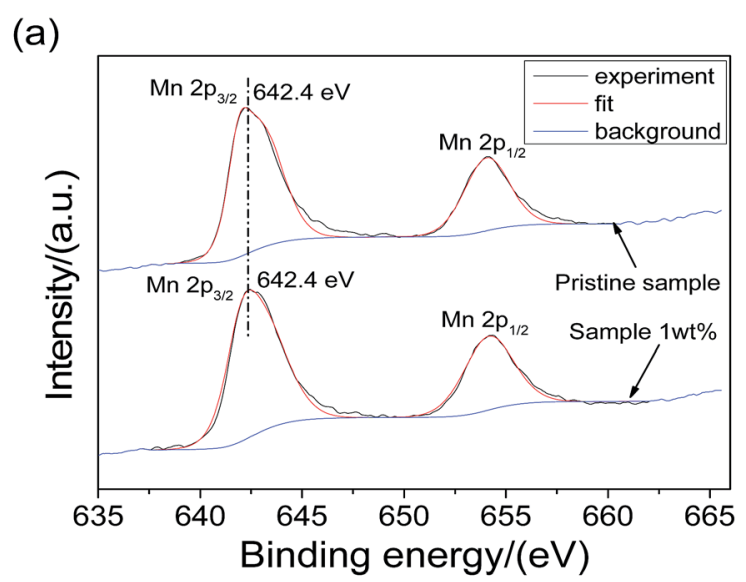

(b)

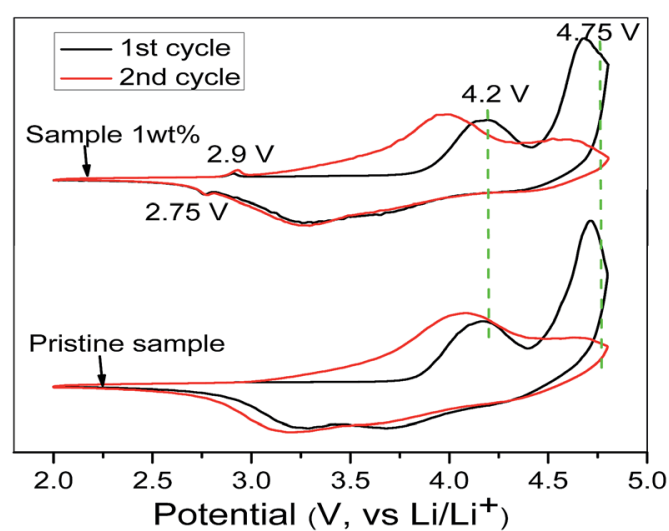

Fig. 4 (a) X-ray photoelectron spectra of $M n 2 p$ and (b) the first two cyclic voltammetric curves of the pristine sample and $1 \mathrm{wt} \%$ sample. one peak is observed in the $1 \mathrm{wt} \%$ sample (Fig. S2 $\dagger$ ). The small peak located at $531.3 \mathrm{eV}$ is generated from the adsorbed oxygen species ( $\mathrm{LiOH}, \mathrm{LiHCO}_{3}$, etc.) remaining in the synthesis process of the lithium-rich oxide. ${ }^{36}$ The spectrum of the $1 \mathrm{wt} \%$ sample does not have this peak, indicating that the adsorbed oxygen species have been perfectly covered by the surface spinel material.

Fig. $4 \mathrm{~b}$ shows the initial two cyclic voltammograms of two samples in the voltage range of $2.0-4.8 \mathrm{~V}$ and at a scan rate of $0.1 \mathrm{mV} \mathrm{s}^{-1}$. The two samples are basically represented by the characteristic CV curves of the lithium-rich layered oxide, except for the fact that the $1 \mathrm{wt} \%$ sample has an extra spinel redox feature peak near $2.75 \mathrm{~V} / 2.9 \mathrm{~V} .^{37,38}$ The oxidation peak at $2.9 \mathrm{~V}$ appeared in the first-cycle cyclic voltammetry curve of the $1 \mathrm{wt} \%$ sample, suggesting that the coated substance is a lithium intercalated cathode material. At the same time, the redox peaks of the spinels $\mathrm{LiMn}_{2} \mathrm{O}_{4}$ and $\mathrm{LiNi}_{0.5} \mathrm{Mn}_{1.5} \mathrm{O}_{4}$ are not observed in the $1 \mathrm{wt} \%$ sample around $4.2 \mathrm{~V}$ and $4.75 \mathrm{~V}$. According to the results of the XPS and CV, it can be concluded that the surface coating crystal material is the spinel $\mathrm{Li}_{4} \mathrm{Mn}_{5} \mathrm{O}_{12}$.

The initial charge/discharge curves of the four samples were recorded under a current density of $20 \mathrm{~mA} \mathrm{~g}^{-1}(0.1 \mathrm{C})$ in a voltage range of 2.0-4.6 V (Fig. 5). The pristine sample exhibits the typical charge/discharge curves of lithium-rich layered oxides, which consist of an uphill sloping curve below $4.4 \mathrm{~V}$, a potential platform between $4.4 \mathrm{~V}$ and $4.6 \mathrm{~V}$ during charging, and a continuous downhill sloping curve during discharging. ${ }^{39-41}$ In addition to the typical charge-discharge curves of the lithium-rich material, the $1 \mathrm{wt} \%$ and $3 \mathrm{wt} \%$ samples also possess small discharge platforms near $2.8 \mathrm{~V}$ in the discharge curve, agreeing with the observations made from Fig. $4 \mathrm{~b}$. However, this small discharge plateau does not appear for the $0.5 \mathrm{wt} \%$ sample. It is indeed observed in the curve of the differential capacity versus voltage plot (Fig. S3†). Therefore, the disappearance of this small platform in the discharge curve may be due to the amount of spinel being too little and the insensitivity of the electrochemical discharge curve. Furthermore, compared with the initial discharge capacity of the pristine sample (236.4 $\mathrm{mA} \mathrm{h} \mathrm{g}^{-1}$ ), the higher initial discharge capacities
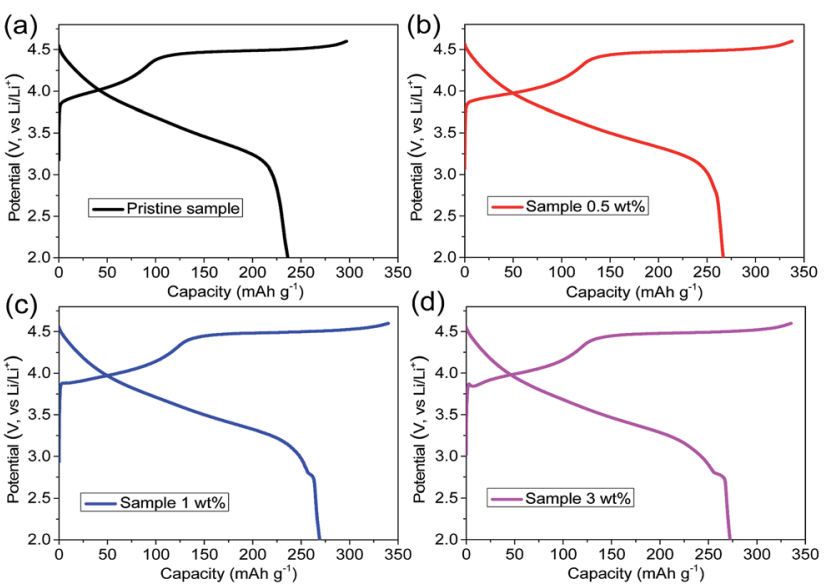

Fig. 5 Initial charge-discharge curves of different samples. 
of the three coated samples are $266.7 \mathrm{~mA} \mathrm{~h} \mathrm{~g}^{-1}(0.5$ wt $\%$ sample), $269.1 \mathrm{~mA} \mathrm{~h} \mathrm{~g}^{-1}$ (1 wt\% sample), and $272.4 \mathrm{~mA} \mathrm{~h} \mathrm{~g}^{-1}$ (3 wt\% sample), respectively. Interestingly, the initial discharge capacity rises along with the increase in the coating amount. It is well known that the discharge capacity of lithium-rich cathode materials is closely related to their chemical composition. The chemical compositions of the four samples were quantitatively analyzed by ICP. As shown in Table 1, the ICP results show that the manganese content in the lithium-rich oxides increases with increasing coating amount. Hence, the increased capacity should be ascribed to the reduction of more $\mathrm{Mn}^{4+}$. In particular, the coating layer maintains a lot of lithium vacancies, resulting in the higher capacity of the coated samples. ${ }^{\mathbf{1 1 4 2}}$ Meanwhile, lithium-rich materials also produce some lithium vacancies in the formation of the spinel layer. These lithium vacancies will provide more sites for $\mathrm{Li}$ ion intercalation in the discharge process, which also results in the increase of the initial discharge capacity of the coated samples.

Fig. 6a shows the discharge capacities of the different samples measured at different current densities. It is found that the $1 \mathrm{wt} \%$ sample has the most superior rate performance, and maintains the maximum discharge capacities of $254 \mathrm{~mA} \mathrm{~h} \mathrm{~g}^{-1}$, $233.7 \mathrm{~mA} \mathrm{~h} \mathrm{~g}^{-1}, 209.9 \mathrm{~mA} \mathrm{~h} \mathrm{~g}^{-1}$, and $166.8 \mathrm{~mA} \mathrm{~h} \mathrm{~g}^{-1}$ at $0.5 \mathrm{C}, 1 \mathrm{C}$, $2 \mathrm{C}$, and $5 \mathrm{C}$, respectively. In particular, the high rate performances of the $0.5 \mathrm{wt} \%$ and $1 \mathrm{wt} \%$ samples are significantly better than those of the $3 \mathrm{wt} \%$ sample and pristine sample. This is due to the fact that the spinel structure has a threedimensional channel for the transportation of lithium ions, which leads to the $0.5 \mathrm{wt} \%$ and $1 \mathrm{wt} \%$ samples having elevated rate discharge capacities. Even at a rate of 10C, the discharge capacity of the $1 \mathrm{wt} \%$ sample can still reach $86.6 \mathrm{~mA} \mathrm{~h} \mathrm{~g}{ }^{-1}$ (Fig. S4 $\dagger$ ). Simultaneously, the diffusion of lithium ions is seriously hindered by the outer layer of the amorphous manganese oxide in the $3 \mathrm{wt} \%$ sample, resulting in the poor rate performance. The rate discharge capacity of the $1 \mathrm{wt} \%$ sample is higher than that of the $0.5 \mathrm{wt} \%$ sample, which can be attributed to the fact that the $1 \mathrm{wt} \%$ sample possesses a more uniform spinel coating and more channels for the transmission of lithium ions. After a certain cycle back to $0.1 \mathrm{C}$, the discharge capacity of the $1 \mathrm{wt} \%$ sample can reach as high as 267.3 $\mathrm{mA} \mathrm{h} \mathrm{g}^{-1}$, showing its excellent electrochemical reversibility.

The cycling performance of the different samples was studied at a discharge current density of $200 \mathrm{~mA} \mathrm{~g}^{-1}$ in a voltage range of 2.0-4.6 V (Fig. 6b). The initial discharge capacity of the $1 \mathrm{wt} \%$ sample can reach $233.2 \mathrm{~mA} \mathrm{~h} \mathrm{~g}^{-1}$ and, after 50 cycles, the
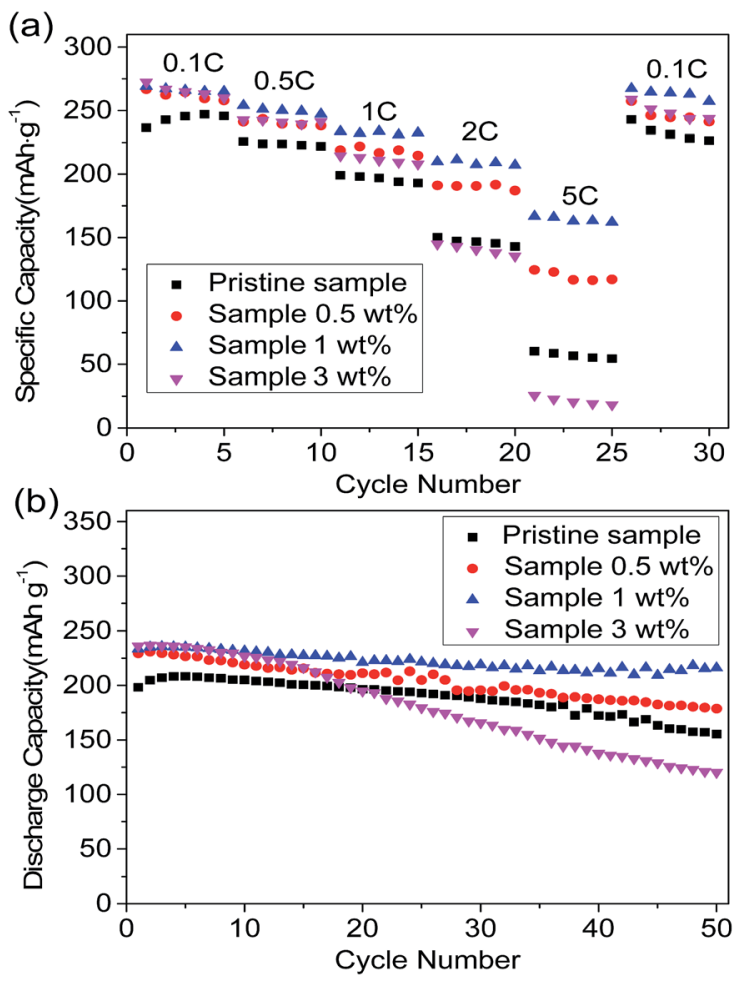

Fig. 6 (a) Rate performance of different samples at various discharge rates. (b) Cyclic performance of different samples at a $1 \mathrm{C}$ discharge rate.

discharge capacity can be maintained at $216 \mathrm{~mA} \mathrm{~h} \mathrm{~g}^{-1}$ (capacity retention of $92.6 \%$ ). The initial discharge capacities of the pristine sample, $0.5 \mathrm{wt} \%$ sample, and $3 \mathrm{wt} \%$ sample are 198.2 $\mathrm{mA} \mathrm{h} \mathrm{g}^{-1}, 229.4 \mathrm{~mA} \mathrm{~h} \mathrm{~g}^{-1}$, and $236.1 \mathrm{~mA} \mathrm{~h} \mathrm{~g}^{-1}$, and the capacity retention rate could be respectively maintained at $78.4 \%, 77.9 \%$, and $50.9 \%$ after 50 cycles. It can be suggested that the cycling performance of the $1 \mathrm{wt} \%$ sample is far more advanced than that of the other samples. The improvement in the cycle performance is attributed to the uniform spinel coating layer that protects the lithium-rich cathode material from corrosion by the electrolyte. Meanwhile, the surfaces of the pristine and "island-type coated" samples are attacked by the $\mathrm{HF}$ in the electrolyte.

The thermal stability of the electrode material is of great concern in terms of the safety of lithium ion batteries. DSC is a useful instrument for recording the thermal reaction between the electrode material and the electrolyte. ${ }^{43}$ Fig. 7 shows the

Table 1 The element content and chemical composition of the samples with an increase in the coating amount

Metal element content

\begin{tabular}{llllll}
\hline Samples & $\mathrm{Li}$ & $\mathrm{Ni}$ & $\mathrm{Co}$ & $\mathrm{Mn}$ & Chemical composition \\
\hline Pristine sample & 1.237 & 0.124 & 0.125 & 0.514 & $\mathrm{Li}_{1.237} \mathrm{Ni}_{0.124} \mathrm{Co}_{0.125} \mathrm{Mn}_{0.514} \mathrm{O}_{2}$ \\
0.5 wt\% sample & 1.220 & 0.124 & 0.127 & 0.529 & $\mathrm{Li}_{1.220} \mathrm{Ni}_{0.124} \mathrm{Co}_{0.127} \mathrm{Mn}_{0.529} \mathrm{O}_{2}$ \\
$1 \mathrm{wt} \%$ sample & 1.213 & 0.125 & 0.127 & 0.535 & $\mathrm{Li}_{1.213} \mathrm{Ni}_{0.125} \mathrm{Co}_{0.127} \mathrm{Mn}_{0.535} \mathrm{O}_{2}$ \\
$3 \mathrm{wt} \%$ sample & 1.210 & 0.121 & 0.124 & 0.545 & $\mathrm{Li}_{1.210} \mathrm{Ni}_{0.121} \mathrm{Co}_{0.124} \mathrm{Mn}_{0.545} \mathrm{O}_{2}$
\end{tabular}




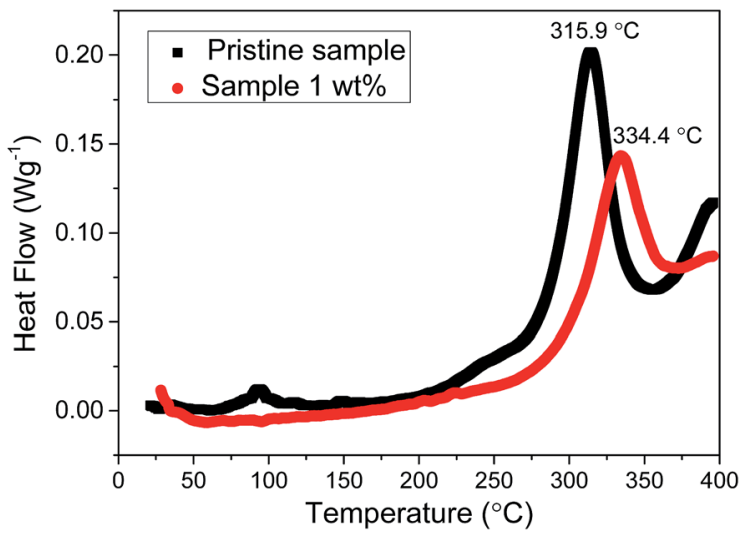

Fig. 7 DSC curves of the pristine sample and $1 \mathrm{wt} \%$ sample at a charge of $4.6 \mathrm{~V}$ and a heating rate of $10{ }^{\circ} \mathrm{C} \mathrm{min}^{-1}$.

DSC curves of the pristine sample and $1 \mathrm{wt} \%$ sample during the initial charge to $4.6 \mathrm{~V}$. The main exothermic peak is near $315.9{ }^{\circ} \mathrm{C}$ for the pristine sample, but this peak shifts to $334.4^{\circ} \mathrm{C}$ for the $1 \mathrm{wt} \%$ sample. On the other hand, the amount of heat produced by the $1 \mathrm{wt} \%$ sample is obviously less than that of the pristine sample if we compare the area of the main exothermic peak. These results suggest that the uniform spinel coating layer can effectively improve the thermal stability of the lithiumrich cathode material.

\section{Conclusions}

In summary, with a variation in the coating amount, the shell structures of the coated samples differ greatly. Through analysis using HRTEM, XRD, and DFT theory calculation, the different shell structures may originate from (1) the limited diffusion of lithium ions from the lithium-rich layered oxide to the coating layer under certain heat-treatment conditions, and (2) the coating amount. The $\mathrm{Li}_{4} \mathrm{Mn}_{5} \mathrm{O}_{12}$ spinel is formed in the coating layer. The sample with the uniform $\mathrm{Li}_{4} \mathrm{Mn}_{5} \mathrm{O}_{12}$ spinel coating layer shows the most excellent electrochemical performance. The initial discharge specific capacity of the $1 \mathrm{wt} \%$ sample is as high as $269.1 \mathrm{~mA} \mathrm{~h} \mathrm{~g}^{-1}$ in the voltage range of 2.0-4.6 V. Even at a rate of $1 \mathrm{C}$, its discharge capacity can still reach up to $233.2 \mathrm{~mA} \mathrm{~h} \mathrm{~g}^{-1}$, and the capacity retention rate is $92.6 \%$ after 50 cycles. Meanwhile, the uniform spinel crystal coated layer can greatly improve the thermal stability of the lithium-rich layered oxide. In addition, it is worth further studying how a thin coating layer can affect the lattice parameters of micro/nano core materials for other material systems.

\section{Conflicts of interest}

There are no conflicts to declare.

\section{Acknowledgements}

This work was supported by the Science and Technology Foundation of Jiangsu (BK20151237), the special nano- technology of Suzhou (ZXG2013004), USTC-NSRL Association funding, and the Collaborative Innovation Centre of Suzhou Nano Science and Technology.

\section{Notes and references}

1 M. Armand and J. M. Tarascon, Nature, 2008, 451, 652-657. 2 A. S. Arico, P. Bruce, B. Scrosati, J. M. Tarascon and W. Van Schalkwijk, Nat. Mater., 2005, 4, 366-377.

3 H. J. Yu, R. Ishikawa, Y. G. So, N. Shibata, T. Kudo, H. S. Zhou and Y. Ikuhara, Angew. Chem., Int. Ed., 2013, 52, 5969-5973.

4 M. Gu, A. Genc, I. Belharouak, D. Wang, K. Amine, S. Thevuthasan, D. R. Baer, J. G. Zhang, N. D. Browning, J. Liu and C. Wang, Chem. Mater., 2013, 25, 2319-2326.

5 N.-S. Choi, J.-G. Han, S.-Y. Ha, I. Park and C.-K. Back, RSC $A d v .$, 2015, 5, 2732-2748.

6 M. Sathiya, G. Rousse, K. Ramesha, C. P. Laisa, H. Vezin, M. T. Sougrati, M. L. Doublet, D. Foix, D. Gonbeau, W. Walker, A. S. Prakash, M. Ben Hassine, L. Dupont and J. M. Tarascon, Nat. Mater., 2013, 12, 827-835.

7 B. Xu, C. R. Fell, M. Chi and Y. S. Meng, Energy Environ. Sci, 2011, 4, 2223-2233.

8 H. Yu and H. Zhou, J. Phys. Chem. Lett., 2013, 4, 1268-1280.

9 C. Yang, Q. Zhang, W. X. Ding, J. Zang, M. Lei, M. S. Zheng and Q. F. Dong, J. Mater. Chem. A, 2015, 3, 7554-7559.

10 W. Yuan, H. Z. Zhang, Q. Liu, G. R. Li and X. P. Gao, Electrochim. Acta, 2014, 135, 199-207.

11 F. Wu, N. Li, Y. Su, H. Lu, L. Zhang, R. An, Z. Wang, L. Bao and S. Chen, J. Mater. Chem., 2012, 22, 1489-1497.

12 Y.-K. Sun, M.-J. Lee, C. S. Yoon, J. Hassoun, K. Amine and B. Scrosati, Adv. Mater., 2012, 24, 1192-1196.

13 H. P. Guo, L. Hu, X. Yi, B. W. Ju, H. Hu, D. Wang and R. Z. Yu, J. Solid State Electrochem., 2014, 18, 1789-1797.

14 B. Li, H. Yan, J. Ma, P. Yu, D. Xia, W. Huang, W. Chu and Z. Wu, Adv. Funct. Mater., 2014, 24, 5112-5118.

15 C. W. Wang, X. L. Ma, J. G. Cheng, L. Q. Zhou, J. T. Sun and Y. H. Zhou, Solid State Ionics, 2016, 177, 1027-1031.

16 P. G. Bruce, B. Scrosati and J.-M. Tarascon, Angew. Chem., Int. Ed., 2008, 47, 2930-2946.

17 M. G. Kim, M. Jo, Y. S. Hong and J. Cho, Chem. Commun., 2009, 45, 218-220.

18 S. H. Kang, C. S. Johnson, J. T. Vaughey, K. Amine and M. M. Thackeray, J. Electrochem. Soc., 2006, 153, A1186A1192.

19 J. Gao and A. Manthiram, J. Power Sources, 2009, 191, 644647.

$20 \mathrm{Y}$. Wu and A. Manthiram, Solid State Ionics, 2009, 180, 50-56. 21 P. K. Nayak, J. Grinblat, M. Levi and D. Aurbach, Electrochim. Acta, 2014, 137, 546-556.

22 B. H. Song, C. F. Zhou, Y. Chen, Z. W. Liu, M. O. Lai, J. M. Xue and L. Lu, RSC Adv., 2014, 4, 44244-44252.

23 M. M. Thackeray, Nat. Mater., 2002, 1, 81-82.

24 A. Kraytsberg and Y. Ein-Eli, Adv. Energy Mater., 2012, 2, 922939.

25 F. Wu, N. Li, Y. F. Su, L. J. Zhang, L. Y. Bao, J. Wang, L. Chen, Y. Zheng, L. Q. Dai, J. Y. Peng and S. Chen, Nano Lett., 2014, 14, 3550-3555. 
26 F. Wu, N. Li, Y. F. Su, H. F. Shou, L. Y. Bao, W. Yang, L. J. Zhang, R. An and S. Chen, Adv. Mater., 2013, 25, 3722-3726.

27 Z. Q. Xie, S. Ellis, W. W. Xu, D. Dye, J. Q. Zhao and Y. Wang, Chem. Commun., 2015, 51, 15000-15003.

28 T. Takata, H. Hayakawa, T. Kumagai and E. Akiba, J. Solid State Chem., 1996, 121, 79-86.

29 S. L. Dudarev, G. A. Botton, S. Y. Savrasov, C. J. Humphreys and A. P. Sutton, Phys. Rev. B: Condens. Matter Mater. Phys., 1998, 57, 1505-1509.

30 Z. Huang, F. Du, C. Wang, D. Wang and G. Chen, Phys. Rev. B: Condens. Matter Mater. Phys., 2007, 75, 054411-054417.

31 N. N. Shukla and R. Prasad, J. Phys. Chem. Solids, 2006, 67, 1731-1740.

32 J. S. Kim, C. S. Johnson, J. T. Vaughey, M. M. Thackeray, S. A. Hackney, W. Yoon and C. P. Grey, Chem. Mater., 2004, 16, 1996-2006.

33 W. S. Yoon, S. Iannopollo, C. P. Grey, D. Carlier, J. Gorman, J. Reed and G. Ceder, Electrochem. Solid-State Lett., 2004, 7, A167-A171.

34 X. Yang, D. Wang, R. Yu, Y. Bai, H. Shu, L. Ge, H. Guo, Q. Wei, L. Liu and X. Wang, J. Mater. Chem. A, 2014, 2, 3899-3911.
35 E. Regan, T. Groutso, J. B. Metson, R. Steiner, B. Ammundsen, D. Hassell and P. Picking, Surf. Interface Anal., 1999, 27, 1064-1068.

36 H. Liu, Y. Yang and J. Zhang, J. Power Sources, 2006, 162, 644-650.

37 M. M. Thackeray, A. Kock, M. H. Rossouw, D. Liles, R. Bittihn and D. Hoge, J. Electrochem. Soc., 1992, 139, 363-366.

38 Y.-K. Sun, Y.-S. Jeon and H. J. Lee, Electrochem. Solid-State Lett., 2000, 3, 7-9.

39 Q. Y. Wang, J. Liu, A. V. Murugan and A. Manthiram, J. Mater. Chem., 2009, 19, 4965-4972.

40 A. R. Armstrong, M. Holzapfel, P. Novak, C. S. Johnson, S. H. Kang, M. M. Thackeray and P. G. Bruce, J. Am. Chem. Soc., 2006, 128, 8694-8698.

41 S. J. Shi, J. P. Tu, Y. Y. Tang, X. Y. Liu, Y. Q. Zhang, X. L. Wang and C. D. Gu, Electrochim. Acta, 2013, 88, 671-679.

42 S. Lee, Y. Cho, H.-K. Song, K. T. Lee and J. Cho, Angew. Chem., Int. Ed., 2012, 51, 8748-8752.

43 H. F. Xiang, B. Yin, H. Wang, H. W. Lin, X. W. Ge, S. Xie and C. H. Chen, Electrochim. Acta, 2010, 55, 5204-5209. 